SVU- International Journal of Veterinary Sciences, 4 (3): 51-69, 2021.

Print ISSN: 2535-1826

Research Article

Open Access

\title{
Vinpocetine Suppresses Inflammatory and Oxidative Machineries in Acute Model of Inflammation-Pivotal Role of COX-2 Signaling
}

\section{Wael Ahmed-Anwar Twafik ${ }^{1}$, Osama Abdel-Raouf Morad ${ }^{2}$, Reham Hassan ${ }^{3,4}$, Khaled A. Nematallah $^{5}$, Dina M.W. Shibat El-hamed ${ }^{6}$, Samy Abdel-Raouf Fahim Morad ${ }^{7 *}$, Noha Abdelmageed $^{8 *}$}

${ }^{1}$ Department of Biochemistry, Animal Health Research Institute (AHRI), Qena branch, Qena, Egypt, ${ }^{2}$ Neurology and Psychological Medicine department, Faculty of Medicine, Sohag University, ${ }^{3}$ Forensic Medicine and Toxicology Department, Faculty of Veterinary Medicine, South Valley University, Qena, 83523, Egypt, ${ }^{4}$ Leibniz Research Centre for Working Environment and Human Factors at the Technical University Dortmund, Dortmund, Germany, ${ }^{5}$ Department of Pharmacognosy, Faculty of Pharmacy, British University in Egypt (BUE), Cairo, Egypt, ${ }^{6}$ Poultry Research Department, Animal Health Research Institute (AHRI), Qena branch, Qena, Egypt, ${ }^{7}$ Department of Pharmacology, Faculty of Veterinary Medicine, South Valley University, Qena, 83523, Egypt, ${ }^{8}$ Department of Pharmacology, Faculty of Veterinary Medicine, Sohag University, Sohag, Egypt.

\section{Abstract}

The presence of inflammation is one of the key factors in the onset and progression of various medical disorders and diseases, making it a crucial challenge for treatment. The purpose of this study is to evaluate antioxidant and anti-inflammatory effects of Vinpocetine, using acute models of inflammation; Xylene-, Carrageenan (CGN)-induced inflammation and acetic acid-induced vascularpermeability in mice were used. We also employed molecular docking approach to verify the underlying mechanism of anti-inflammatory activity of Vinpocetine. In a current investigation, Vinpocetine showed anti-inflammatory and antioxidant effects on Xylene- and CGN-induced inflammation in a dose-dependent manner. Vinpocetine reduced inflammatory edema and restored antioxidant tissue balance, probably via suppression of IL-1 $\beta$, IL-6, TNF- $\alpha$, MDA and MPO activity, and also through increased non-enzymatic antioxidant (GSH) levels in paw tissue. Histopathological examination showed that Vinpocetine restored normal skin architecture with significant inhibition of tissue edema, congestion, and cellular infiltration in CGN-challenged paw. Mechanistically, Vinpocetine showed downregulation the expression of COX-2 protein, in western blot assessment, that was associated with significant decrease in the level of prostaglandin E 2 (PGE2) levels; a major metabolic product of COX-2 enzyme. Interestingly, Silico study showed that Vinpocetine has strong affinity to COX-2, similar to diclofenac, suggested possible mechanism of downregulation of COX2 expression. Therefore, Vinpocetine showed antioxidant and anti-inflammatory responses might, in part, due to inhibition of COX-2/PGE 2 pathway.

Keywords: COX-2/PGE 2 pathway, Cytokines, Oxidative stress, Vinpocetine.

DOI: 10.21608/svu.2021.70729.1119 Received: April 2, 2021 Accepted: August 15, 2021 Published: September 7, 2021 *Corresponding Authors: Dr. Noha Abdelmageed E-mail: nohafoud@gmail.com, and Prof. Dr. Samy Morad_E-mail:morads@vet.svu.edu.eg Citation: Twafik et al., Vinpocetine Suppresses Inflammatory and Oxidative Machineries in Acute Model of Inflammation-Pivotal Role of COX-2 Signaling. SVU-IJVS 2021, 4 (3): 51-69.

Copyright: (C) Twafik et al. This is an open access article distributed under the terms of the creative common attribution license, which permits unrestricted use, distribution and reproduction in any medium provided the original author and source are created.

Competing interest: The authors have declared that no competing interest exists. 


\section{Introduction}

Inflammation is considered the early physiological response to tissue damage associated with a complex cascade of reactions that can be motivated by numerous agents such as toxic compounds, microbes, etc. (Chen et al., 2018). Cellular changes that occur during acute inflammatory conditions play a potential role in inhibiting the spread of infection and restoring normal tissue function. The acute inflammatory events are generally comprised of four sub-events distinctly into (1) fluid exudation for supplying plasma proteins to the area of injury; (2) neutrophil infiltrations lead to removing pathogens and cellular portions; (3) vasodilation facilitate the delivery of imperative proteins and cells (like exudation) and elevating tissue temperature; (4) pain and function impairment help to oblige rest and minimize the possibility of further tissue injury. Taking into consideration, if the inflammation is left unmanaged, it could act as an etiologic factor for many other illness (Helm and Rudel, 2020; Adegbaju et al., 2020; S. Chen et al., 2020; Dludla et al., 2020; Mazzaferro et al., 2021; Charlton et al., 2020; Andrianova et al., 2020).

Major events during the inflammatory cascade are activation of MPO and lipid peroxidation, increase cytokines release, and perhaps the most important, neutrophilderived reactive oxygen species (ROS) generation (Yoshikawa, 2006; Medzhitov, 2008; Aratani et al., 2012; Bryan et al., 2012; Mittal et al., 2014; Lauridsen, 2019). Vascular permeability increases fluid and cellular extravasation which trigger a localized edema noted in the inflammatory process. It has been well acknowledged (Nidavani et al., 2014) that the injection of acetic acid I.P markedly promotes vascular permeability and encourages the vascular leakage of Evans blue dye. Using Evans blue dye, it is possible to assess the impact of pathological changes in numerous disorders such as, immunological disorders, inflammatory disorders, and inflammatory diseases like diabetes, myocardial infarction, rheumatoid, and others.

Free radicals are significant mediators that provoke inflammation and, subsequently, their neutralization by antioxidants and radical scavengers can mitigate inflammatory processes. In order to diminish the damage outcome by ROS, the organism utilizes numerous enzymes such as superoxide dismutase (SOD) and catalase (CAT) and nonenzymatic element such as glutathione (GSH) (Nathan, 2002). Currently, the basic treatment during acute inflammatory condition is the use of nonsteroidal anti-inflammatory drugs (NSAIDs), definitely to restrict neutrophil migration and oxygen free-radical generation, but several kinds of research confirmed that extended use could lead to a serious side effect, such as cardiovascular and gastrointestinal complications (Baptista et al., 2018).For this reason, it is imperative to find new anti-inflammatory therapy with minimum side effects and maximum efficiency is required.

Vinpocetine is a derivative of the alkaloid Vincamine extracted from the periwinkle plant, Vinpocetine is a selective inhibitor of phosphodiesterase type 1 (PDE1) that has potent neurological effects via inhibition of voltage-gated NA channel and reduction of neuronal $\mathrm{CA}$ influx. Vinpocetine has been proved as antioxidant, anti-inflammatory, and antiapoptotic effects with inhibitory effect (Zhang et al., 2018).

This study will examine the evidence for the anti-inflammatory activities of Vinpocetine in the acute standard model of acute inflammation.

\section{Materials and methods}

\section{Drugs and chemicals}

Vinpocetine, Xylene, $\lambda$-Carrageenan, Diclofenac, Evans blue dye, and diclofenac sodium, were purchased from SigmaAldrich Co. (USA). Vinpocetine and Diclofenac were freshly suspended in non- 
pyrogenic $0.9 \% \mathrm{NaCl}$. All other chemicals and solvents used in the study were of the highest grade commercially available.

\section{Animals and ethics statement}

The experiments were carried out on 42 healthy male mice (6-8 weeks old, $25 \pm 5 \mathrm{~g}$ ). Animals were obtained from the breeding colony maintained at the animal house of the Faculty of Veterinary Medicine (SVU, Qena, Egypt). All animals were housed under conventional laboratory conditions throughout the period of experimentation at room temperature of 25 $\pm 2^{\circ} \mathrm{C}, \quad 60-70 \%$ humidity, and 12-h light/dark cycle, fed standard feeding pellets (20\% proteins, 5\% fats, and $1 \%$ multivitamins), and allowed free access to tap water. Animals were allowed at least one week of acclimatization before experiments. All animal experiments were approved and carried out according to "the Guide for the Care and Use of Laboratory Animals, Animal Care Committee" of SVU University.

\section{Experimental design}

\section{Evaluation of anti-inflammatory activities}

\section{Xylene-induced ear edema in mice}

The Xylene-induced ear edema-model was initially used to screen and assess the anti-inflammatory properties of Vinpo at different doses. Acute Inflammation was induced in mice using the topical application of $50 \mu \mathrm{L}$ xylene at the anterior and posterior surface of the right ear, for a period of $15 \mathrm{~min}$. Albino mice were randomized and divided into seven groups of six mice per group. The control group (Ctrl): mice received $10 \mathrm{ml} / \mathrm{kg}$ of saline and served as control. Positive control (Xylene Group): Xylene was applied topically on both ear surfaces (the anterior and posterior surfaces) of the right ear, and the left ear was considered as negative control. Vinpocetine groups (Vinpo); Four different concentrations of Vinpo (3, 10, 30, and 100 $\mathrm{mg} / \mathrm{kg}$ ) were intraperitoneally injected 30 min before xylene application. After four hours of xylene application, the animal was sacrificed, both ears were removed and ear discs of $6 \mathrm{~mm}$ in size/diameter were punched out and weighed. The average weight difference between the right and left ear was calculated as a measure for inflammatory response. The difference between ear weights was recorded as edema induced by xylene.

\section{Acetic acid-induced peritoneal vascular permeability test}

Forty two male mice were divided into seven groups, each group consists mice: Vehicle (Group 1), mice were received only saline; Acetic acid (positive, Group 2), mice were intraperitoneally injected with $0.7 \%$ (v/v) acetic acid; Diclofenac, $20 \mathrm{mg} / \mathrm{kg}$, i.p.(Group 3); Vinpo at dose of $3 \mathrm{mg} / \mathrm{kg}$, i.p., (Group 4); Vinpo at dose of $10 \mathrm{mg} / \mathrm{kg}$, i.p. (Group 5); Vinpo at dose of $30 \mathrm{mg} / \mathrm{kg}$, i.p., (Group 6) and Vinpo at dose of 100 $\mathrm{mg} / \mathrm{kg}$, i.p. (Group 7). Briefly, the animals in 3rd and 4th -7 th groups were pretreated for $1 \mathrm{hr}$ with diclofenac and Vinpo, respectively, and subsequently, all mice, except Group 1, were intraperitoneally injected with $0.7 \%(\mathrm{v} / \mathrm{v})$ acetic acid in saline $(10 \mathrm{ml} / \mathrm{kg})$, with simultaneous intravenous injection with Evans blue dye (2\%, 10 $\mathrm{ml} / \mathrm{kg}$ ). After $20 \mathrm{~min}$, all mice were sacrificed and then the escaped dye into the abdominal cavity of each mouse was collected by rinsing the abdominal cavity with $5 \mathrm{ml}$ of normal saline. The collected solution was centrifuged, at $3000 \mathrm{rpm}$ for 10 min, and the absorbance of the supernatants were assessed colorimetrically at a wavelength of $590 \mathrm{~nm}$.

\section{CGN-induced paw edema in mice}

The anti-inflammatory potential of the Vinpo was determined by using CGNinduced paw edema. Briefly, of $50 \mu \mathrm{L}$ of a freshly prepared $\lambda$-carrageenan $(1 \%$, saline) was injected in the left hind paw pad of animal. As a control, $50 \mu \mathrm{L}$ saline solutions were injected into the right hind paw. Four 
different concentrations of Vinpocetine were injected intraperitoneally $(3,10,30$, and $100 \mathrm{mg} / \mathrm{kg}$ ), $1 \mathrm{hr}$ before sub-planter injection of carrageenan. Paw edema was then measured using a digital caliber at 0,1 , 3 , and $6 \mathrm{hrs}$.

The anti-inflammatory activity was determined with the trapezoidal mathematical approach; where obtained data at different times point (from 0 to $6 \mathrm{hrs}$ ) were plotted to obtain the area under the curve (AUC); time against the volume of paw edema. The total anti-inflammatory activities of escalated dosses of Vinpo were estimated based on the percentage of the AUC compared to the control-non treated group.

\section{Sampling}

After complete assessment of the paw volume, mice were sacrificed by cervical dislocation, and paws were removed by cutting at the tibiotarsal level. Immediately after the animals were sacrificed, the paws were rinsed in a Tris buffer $(\mathrm{pH} \mathrm{7.4)}$ to remove any blood and clots. Then, the paws were degloved to remove the bone. The paw's tissues were immediately frozen in liquid nitrogen and kept at $-80{ }^{\circ} \mathrm{C}$ until used for analysis.

Paw tissues were cleaned with ice-cold saline, and immediately were homogenized in $\mathrm{KCl}$ solution $(1.15 \%$, w/v), in a PotterElvehjem tissue grinder with Teflon pestle, to give a $10 \%$ homogenate. After centrifugation $\left(200 \mathrm{~g}, 10 \mathrm{~min}, 4^{\circ} \mathrm{C}\right)$, the supernatants were used for measuring MDA, GSH, CAT and SOD levels.

\section{Measurement of paw lipid peroxide measured as malondialdehyde (MDA)}

Paw MDA levels were measured colorimetrically using a commercially available Biodiagnostic kit (Cat \# MD 2529, Dokki, Giza, Egypt). The formed color following the reaction of thiobarbituric acid with the tissue homogenate was measured at an optical density of $535 \mathrm{~nm}$. Paw MDA concentrations were expressed as $\mathrm{nmol} / \mathrm{g}$ tissue.

\section{Measurement of paw reduced glutathione (GSH)}

GSH contents were quantified using a biodiagnostic kits (Cat \# GR2511 Dokki, Giza, Egypt). The principle of this procedure is based on the formation of " 2 nitro-5- mercaptobenzoic acid" from the reduction of "bis (3-carboxy-4-nitrophenyl) disulfide "reagent by the $\mathrm{SH}$ - group, which has a yellow color that was measured colorimetrically at $412 \mathrm{~nm}$. Paw GSH concentrations were expressed as $\mathrm{mmol} / \mathrm{g}$ tissue

\section{Measurement of paw catalase enzyme activity (CAT)}

Paw CAT activity was determined by using a biodiagnostic kits (Cat \# CA 2517, Dokki, Giza, Egypt). This assay depends on the reaction of $\mathrm{H}_{2} \mathrm{O}_{2}$ with "3,5-dichloro-2hydroxybenzene sulfonic acid" and 4aminophenazone, forming a colored chromophore that could measure at $510 \mathrm{~nm}$. CAT activity was expressed in $\mathrm{U} / \mathrm{g}$ tissue.

\section{Measurement of paw superoxide dismutase enzyme activity (SOD)}

Paw SOD activity was determined by using a biodiagnostic kit (Cat \# CA 2511, Dokki, Giza, Egypt). This assay based on the ability of the SOD to inhibit the phenazine methosulphate (PMS)-mediated reduction of nitroblue tetrazolium (NBT) dye. SOD activity was expressed in $\mathrm{U} / \mathrm{g}$ tissue.

\section{Assessment of pro-inflammatory cytokines}

To evaluate cytokines in paw tissue, piece of paw tissue was homogenized with ice-cold saline (contain protease inhibitors) in a ratio $1: 10 \quad(\mathrm{w} / \mathrm{v})$ to form $10 \%$ homogenate. After centrifugation $(16,000 \times$ $\mathrm{g}, 4{ }^{\circ} \mathrm{C}$ for $\left.10 \mathrm{~min}\right)$, the levels of interleukin- 
$1 \beta$ (IL-1 $\beta$, Cat\#BMS6002, ThermoFisherScientific, USA), interleukin-6 (IL-6, Cat\#88-7064-88, ThermoFisher-Scientific, USA), and tumor necrosis factor- $\alpha$ (TNF- $\alpha$, Cat\#BMS607-3, ThermoFisher-Scientific, USA) in the paw tissue supernatants were measured using a commercially available ELISA kits (ThermoFisher-Scientific, USA), according to the manufacturer's protocols for each respective kit. Data were expressed as pg/mg tissue for IL-1 $\beta$, IL-6 and $\mathrm{ng} / \mathrm{g}$ for TNF- $\alpha$. Additionally, Paw levels of PGE2 were determined using a commercially available ELISA kit (BMS607-3, ThermoFisher-Scientific, USA), following the manufacturer's protocol and the data were expressed as $\mathrm{pg} / \mathrm{gm}$ tissue.

\section{Measurement of paw myeloperoxidase (MPO)}

The extent of neutrophil migration and accumulation in mice paw tissue was indirectly measured by the MPO kineticcolorimetric activity assay. Briefly, fifty $\mathrm{mg}$ of paw tissue was homogenized in 10 $\mathrm{mM}$ potassium phosphate buffer $(\mathrm{pH} 7.0)$ containing $0.5 \%$ hexadecyl trimethylammonium bromide (HTAB, $1 \mathrm{ml}$ buffer per $50 \mathrm{mg}$ of tissue). The tissue homogenates were then centrifuged at $16,000 \times g$ and $4{ }^{\circ} \mathrm{C}$ for $10 \mathrm{~min}$. The MPO enzyme activity was assessed by allowing supernatant aliquot to react with a $1.6 \mathrm{mM}$ tetramethylbenzidine/ $0.1 \quad \mathrm{mM} \quad \mathrm{H}_{2} \mathrm{O}_{2}$ solution. The rate of absorbance shift was measured at $450 \mathrm{~nm}$. One unit of MPO activity was defined as the activity required to convert $1 \mu \mathrm{mol}$ of hydrogen peroxide to water at $22-37{ }^{\circ} \mathrm{C}$ in $1 \mathrm{~min}$. The results are represented as MPO units/g of tissue.

\section{Histopathological examinations of paw}

Hind paw from different groups was excised, fixed in $10 \%$ formalin, embedded in paraffin blocks from which $5 \mu$ thick sections were obtained. Sections were stained with Hematoxylin and Eosin dye and then evaluated under a light microscope.

\section{Western blot analyses}

Paw tissues were homogenized and lysed with RIPA lysis buffer (Cat\#R0278, Sigma-Aldrich) on ice in $30 \mathrm{~min}$, and then the lysates were collected by centrifugation $10,000 \times \mathrm{g}$ at $4^{\mathrm{O}} \mathrm{C}$ for $20 \mathrm{~min}$. The lysates (protein) were subjected to SDS-PAGE separation, according to previous protocol (Morad, Messner, et al., 2013). Primary antibodies against COX-2 (1:1500, Cayman Chemical Co., Michigan, and USA) and horseradish peroxidase conjugated secondary antibodies $\left(1: 2000,22^{\circ} \mathrm{C}, 1 \mathrm{~h}\right)$ were used for immunoblotting analysis. $\beta$ actin (\# 4970, Cell Signaling Technology, MA, USA) was used as housekeeping protein. All experiments were performed in triplicates. The relative band intensities were measured using imageJ software (NIH, Bethesda, Bethesda, MD).

\section{In silico studies: virtual screening for interaction of Vinpocetine and diclofenac with $\mathrm{COX}-2$ enzymes by molecular docking}

The molecular docking approach was conducted according to the previous protocol (Abdelmageed et al., 2021) and performed with Molegro Virtual Docker 5 (Morad, Schmid, et al., 2013). In brief, the crystal structures of COX -2 enzymes (PDB ID: 1PXX, with $2.9 \AA$ resolution) complexes with diclofenac as standard COX-2 inhibitor was downloaded from PDB database. Vinpocetine structure was obtained from PubChem with CID: 443955 and energy minimized using OPLS2005 force-field. Final visualization of VinpCOX-2 interaction was performed by using BIOVIA Visualizer (BIOVIA Discovery Studio v.4.5, Accelrys). All software programs were run on a workstation of Windows7, Motherboard of Intel 5th Generation, 250 GB SSD, 20 GB Ram. 


\section{Results}

Assessment of anti-inflammatory Activities of Vinpocetine

\section{Impact of vinpocetine on xylene-induced ear edema model}

As shown in Fig. 1, Xylene-induces visible redness of the right ear (Fig. 1A). The average weight of the ears and the percentage of inhibition of inflammation are calculated and illustrated in Fig. 1B. Xylene topical application caused observable edema as indicated by the increases of weight of the right ear (23.61 $\pm 2.1 \mathrm{mg}$ ) when compared to the control left ear (Fig. 1B). Administration of Vinpo at different doses; 3, 10, 30, and $100 \mathrm{mg} / \mathrm{kg}$, (I.P.) elicited a variant degree of reduction in ear weight $(20.23 \pm 2.74,18.25 \pm 1.52$, $11.33 \pm 2.31$ and $5 \pm 2.24 \mathrm{mg}$, Fig. 1B), respectively. The inhibition of ear inflammation by Vinpo was prominent at both $30,100 \mathrm{mg}(52.44 \pm 5.84 \%, 79.36 \pm$ $7.86 \%$, Fig. 1B-C), respectively. Thus, we can conclude that Vinpo suppressed xyleneinduced ear edema in mice a dosedependent manner.

\section{Impact of Vinpocetine on acetic acid- induced peritoneal vascular permeability}

Vinpo treatment mice evoked a significant $\quad(\mathrm{P}<0.001) \quad$ dose-related suppression of acetic acid induced_vascular permeability compared to vehicle group (Fig. 1E), demonstrating the overwhelming of the vascular response in the acute inflammation process. Similarly, the reference drug diclofenac $(20 \mathrm{mg} / \mathrm{kg}$, i.p.), also produced a significant inhibitory effect on peritoneal capillary permeability. These data proved evidence that Vinpo significantly mitigated acetic acid-induced capillary permeability.

\section{Impact of vinpocetine on CGN-induced paw edema model}

The anti-inflammatory activities of Vinpo on the paw edema induced by carrageenan are shown in Fig. 2. Pathological phenomena observed on mice paws were photographed and the photographic results showed that the mice paw underwent significant swelling after the injection of carrageenan (Fig. 2A).

The time-dependent curve shows that the paw size increased and reached a maximum at $3 \mathrm{~h}(3.63 \pm .23 \mathrm{~mm})$ after carrageenan injection. The extent of paw edema, over time, was plotted along a time and converted into the area under the curve (AUC) scores (Fig. 2B)

AUC analysis curve (Fig. 2B) and analysis (Fig. 2C) shows that administration of Vinpo (I.P) at doses 3, 10, 30, and 100 $\mathrm{mg} / \mathrm{kg}$, (I.P.) $1 \mathrm{hr}$ prior to the carrageenan sub-plantar injection significantly reduced the development of paw edema compared to that vehicle-treated group at 1-6 hr. Vinpo 100 produced a greatest reduction in paw edema, even after $1 \mathrm{~h}$ of carrageenan induction, the maximum effect (75.96 \pm $6.09 \%$ inhibition of pawed edema) was observed at $3 \mathrm{~h}$ (Fig. 3B). While, Vinpo at 3, 10 and $30 \mathrm{mg}$ exhibited mild to moderate anti-inflammatory activity range from 7.82 $\pm 0.44,17.61 \pm 1.59$ and $43.59 \pm 3.91 \%$, respectively (Fig. 1C-D). These observations reflect the ability of Vinpo to attenuate the inflammatory alterations following carrageenan sub-plantar injection in a dose-dependent manner. 

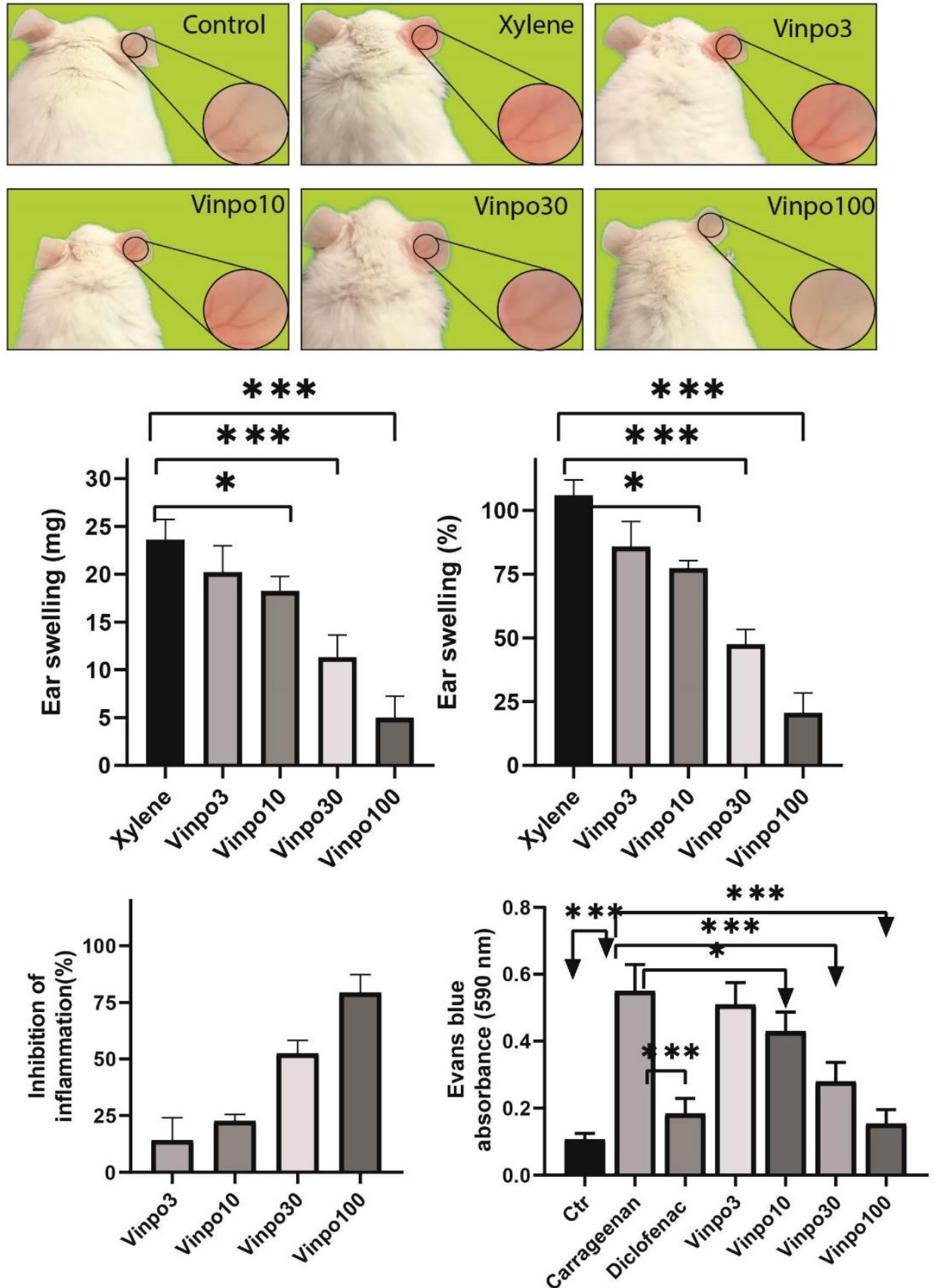

Fig. 1. Inhibitory effect of vinpocetine on xylene-induced acute topical edema.

The mice were pretreated with various doses of Vinpocetine $(3,10,30$, and $100 \mathrm{mg} / \mathrm{kg}$ ) intraperitoneally $30 \mathrm{~min}$ before xylene smeared on the anterior and posterior surfaces of the right ear. (A) Gross appearance/lesion of ears treated with different agents. (B) Ear swelling (mg). (C) Percentage of ear swelling. (D) Percentage of anti-inflammatory activity. (E) Inhibitory effect of vinpocetine on acetic acid-induced peritoneal vascular permeability model. The mice were pretreated with various doses of Vinpocetine $(3,10,30$, and $100 \mathrm{mg} / \mathrm{kg}$ ). After $1 \mathrm{~h}$, mice were intraperitoneally injected with $0.7 \%(\mathrm{v} / \mathrm{v})$ acetic acid in saline $(10 \mathrm{ml} / \mathrm{kg})$, with simultaneously injected intravenously with Evans blue dye $(2 \%, 10 \mathrm{ml} / \mathrm{kg})$. Vinpo3; Vinpocetine at dose $3 \mathrm{mg} / \mathrm{kg}$, Vinpo10; Vinpocetine at dose $10 \mathrm{mg} / \mathrm{kg}$, Vinpo30; Vinpocetine at dose $30 \mathrm{mg} / \mathrm{kg}$, and Vinpo100; Vinpocetine at dose $100 \mathrm{mg} / \mathrm{kg}$. Data are expressed as the mean \pm S.D. of 6 mice for each group. ${ }^{*} p<0.05, * * p<0.01$ and $* * * p<0.001$ compared with vehicle/or positive control. 

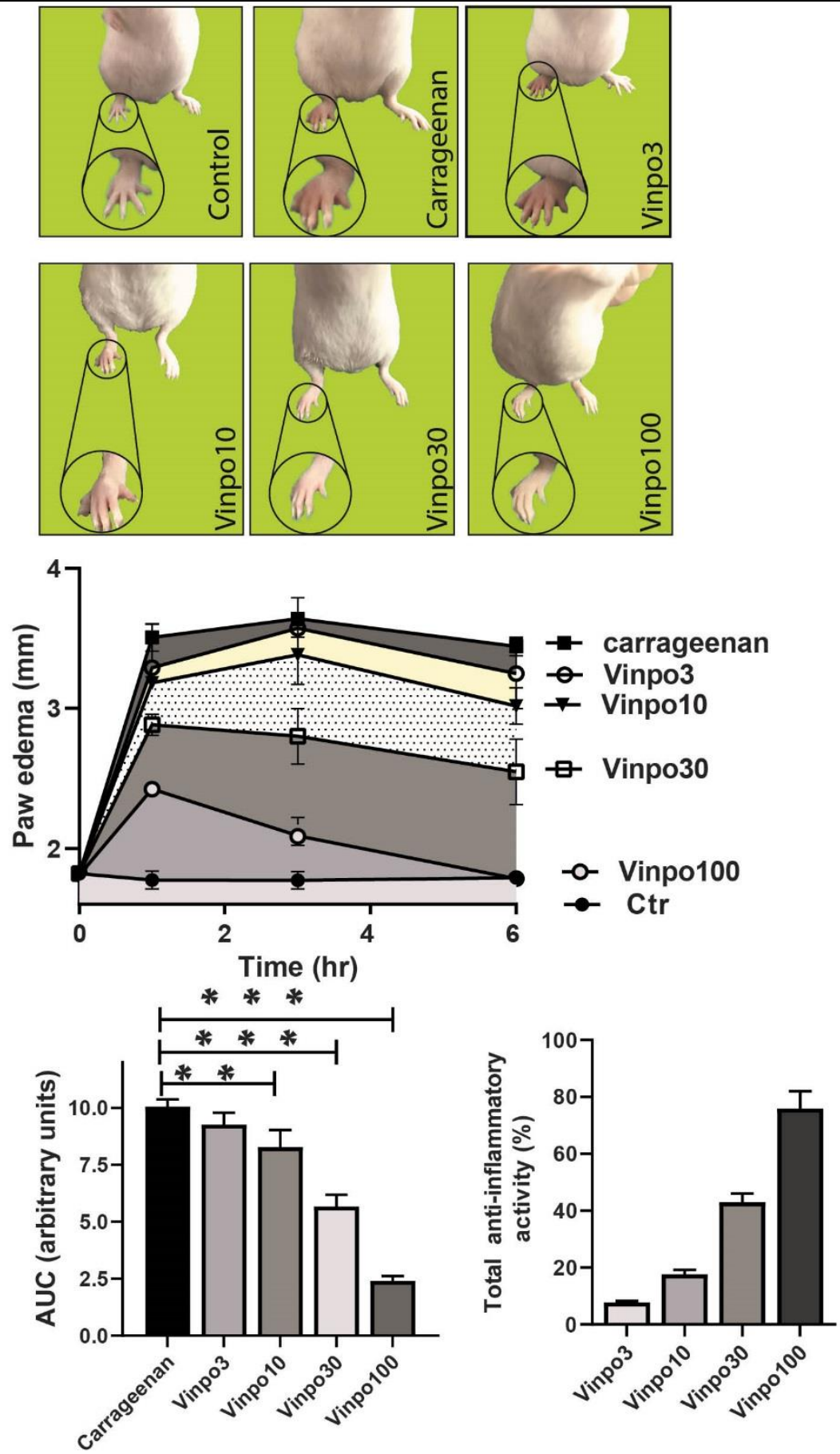

Fig. 2. Inhibitory effect of vinpocetine on CGN -Induced paw edema.

Footpad edema was induced by injection of $50 \mu \mathrm{l}$ Carrageenan (1\% w/v in saline, sub.pl.) and was evaluated by micrometer electronic digital caliber. Vinpocetine $(3,10,30$, and $100 \mathrm{mg} / \mathrm{kg})$, i.p administered at $1 \mathrm{~h}$ before injection of Carrageenan. Paw volume was measured before the sub plantar injection and hourly up to $6 \mathrm{hrs}$. (A) Gross appearance/lesion of paws treated with different agents. (B) Paws volume were measured hourly up to $6 \mathrm{hrs}$. (C) Calculated AUC. (D) Percentage of total anti-inflammatory activity of Vinpocetine. Vinpo3; Vinpocetine at dose 3 $\mathrm{mg} / \mathrm{kg}$, Vinpo10; Vinpocetine at dose $10 \mathrm{mg} / \mathrm{kg}$, Vinpo30; Vinpocetine at dose $30 \mathrm{mg} / \mathrm{kg}$, and Vinpo100; Vinpocetine at dose $100 \mathrm{mg} / \mathrm{kg}$. Data are expressed as the mean \pm S.D. of 6 mice for each group. ${ }^{* *} \mathrm{p}<0.01$ and $* * * \mathrm{p}<0.001$ compared with vehicle/or positive control. 


\section{Effects of Vinpocetine on the histological} changes associated with carrageenan injection

A histopathological study was carried out in paw tissue $6 \mathrm{hrs}$ after the induction of inflammation, as illustrated in Fig. 3. $\mathrm{H}$ \& E-stained paw tissue of mice in the negative control group (I) showed no inflammation with a conventional structure. Contrariwise, the carrageenan group (II) showed edema formation and marked accumulation of infiltrating inflammatory cells with serious alterations in tissue architecture (Fig. 3AB). VINPO 3, 10 groups (IV) showing significant inflammation and marked cell damage $(56.27 \%$ cellular infiltration). VINPO 30 group (V) revealed only a few scattered inflammatory cells $(31.24 \%$ cellular infiltration). Interestingly, these signs of inflammation in the VINPO 100 group (VI) markedly suppressed the indicated changes, with minimal infiltration (2.17\%).

To elucidate the migration and accumulation of leukocytes into the inflamed tissue, the level of MPO was measured CGN-challenged mice showed a significant increase $(p<0.001)$ in the level of MPO in the paw tissue (Fig. 3C). Simultaneously, vinpocetine administration significantly ameliorated $(p<0.0001)$ the increase of the level of MPO, with all tested doses of Vinpo), compared to the carrageenan injected group.

Overall, histopathologic findings were scored for inflammation (infiltration, congestion, and edema) on a 7 -grade scale from 0 to 6 (normal $=0$, mild $=1,2=$ mild $/$ moderate, $3=$ moderate, $4=$ moderate $/$ sever, $5=$ sever, and $6=$ the most severe inflammation) and illustrated in Fig. 3D.

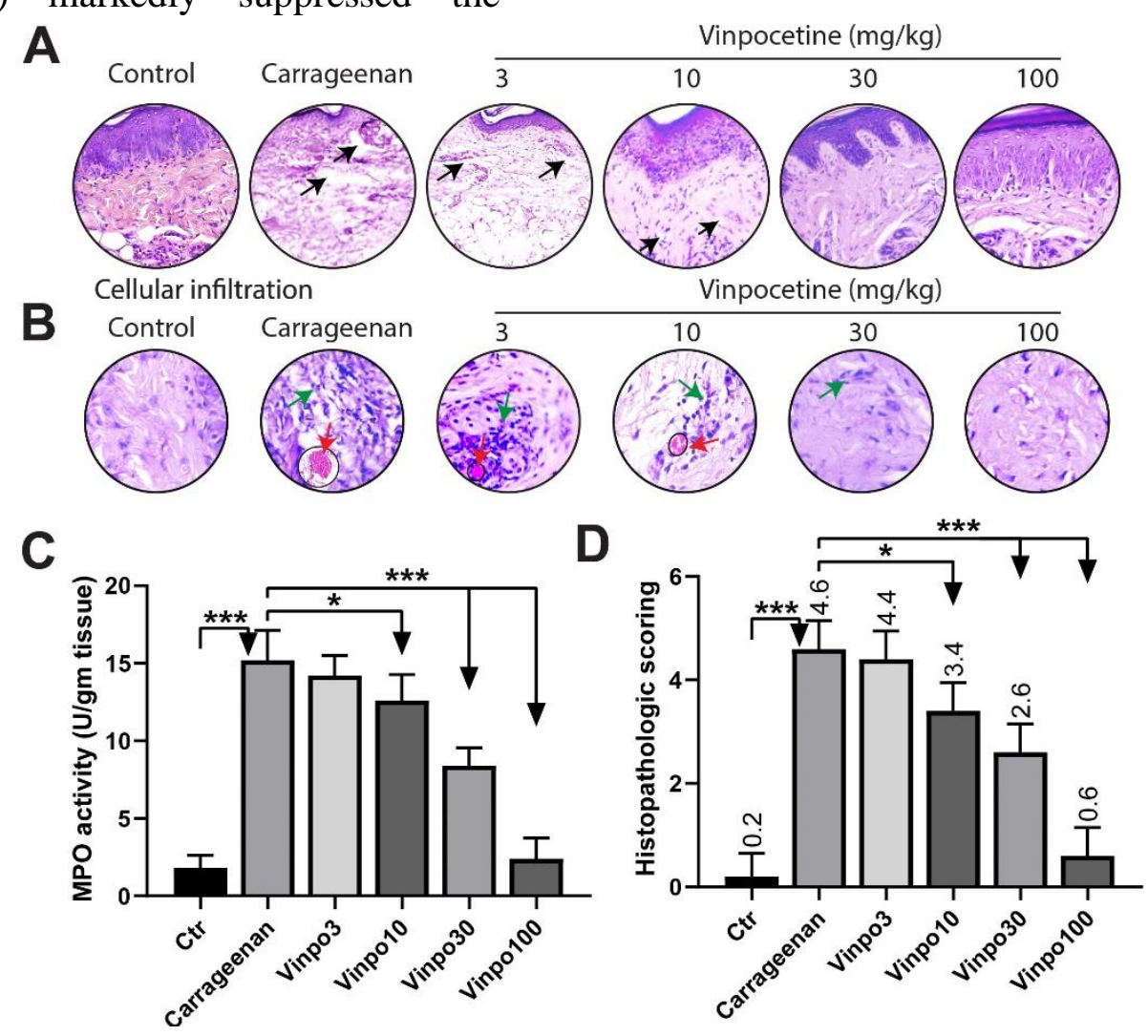

Fig. 3. Effects of vinpocetine on Histopathological changes of CGN -induced paw edema in mice

Histological evaluation was performed by hematoxylin and eosin staining. A) No obvious alterations or cell infiltration were observed in the control group. Carrageenan injected paw shows edematous swelling (black arrow) of the paw tissue with a loss of the physiological 
architecture compared to control group. Vinpocetine-treated mice show a reduction in edematous swelling, in dose dependent manner. (B) Carrageenan injected paws show cellular infiltration (green arrow) and congestion (red arrow), while Vinpocetine-treated mice show a reduction in cellular infiltration and congestion, in dose dependent manner. (C) MPO activity (u/mg). (D) Histopathological scoring; histopathologic findings were scored for inflammation (infiltration, congestion, and edema) on a 7 -grade scale from 0 to 6 (normal $=0$, mild $=1,2=$ mild/ moderate, 3=moderate, $4=$ moderate/ sever, $5=$ sever, and $6=$ the most severe inflammation). Vinpo3; Vinpocetine at dose $3 \mathrm{mg} / \mathrm{kg}$, Vinpo10; Vinpocetine at dose $10 \mathrm{mg} / \mathrm{kg}$, Vinpo30; Vinpocetine at dose $30 \mathrm{mg} / \mathrm{kg}$, and Vinpo100; Vinpocetine at dose $100 \mathrm{mg} / \mathrm{kg}$. Data are expressed as the mean \pm S.D. of 6 mice for each group. ${ }^{*} \mathrm{p}<0.05$ and $* * * p<0.001$, compared with vehicle/or positive control.

\section{Effect of Vinpocetine on the oxidant and antioxidant status in the paw}

To examine the enzymatic activities and non-enzymatic antioxidant levels in experimental groups, we measured GSH (non-enzymatic), SOD and CAT (enzymatic) activities in paw tissue homogenates and illustrated in Fig. 4. Injection of carrageenan was found to be associated with a prominent disturbance of cellular redox status in the paw tissue as confirmed by a significant $(\mathrm{p}<0.001)$ depletion of the antioxidants including GSH (Fig. 4A), CAT (Fig. 4B), and SOD (Fig. 4C) activities, coupled with marked elevation of MDA level (Fig. 4D), with respect to the normal mice.

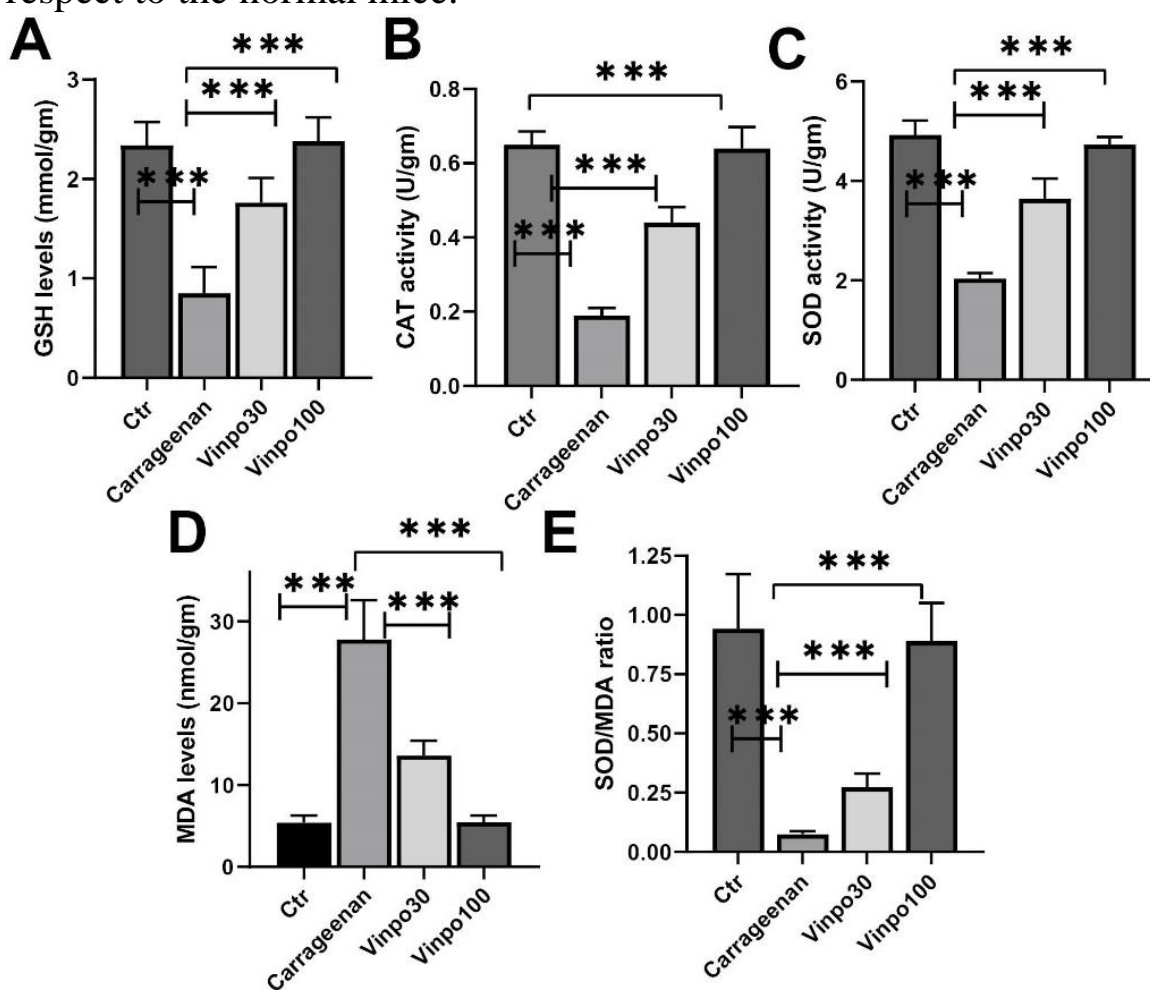

60
In contrast, Vinpo-challenged mice showed significant reduction $(\mathrm{P}<0.001)$ in the level of MDA and marked enhancement of the antioxidant capacity, GSH (Fig.4A), CAT (Fig. 4B), and SOD (Fig. 4C) activities, when compared to CGNchallenged mice.

By Using SOD/MDA ratio to evaluate the overall cellular oxidant and antioxidant status, Fig. 4E shows that both Vinpo at 30 and $100 \mathrm{mg} / \mathrm{kg}$ exhibited a significant antioxidant capacity against $\mathrm{CGN}$-induced oxidative stress, with a distinguishable activity can be achieved by using Vinpo at dose of $100 \mathrm{mg} / \mathrm{kg}$.

Fig. 4. Antioxidant activities of Vinpocetine against CGN-induced oxidative stress in paw model.

Vinpocetine (30, and 100 $\mathrm{mg} / \mathrm{kg}$ ), i.p administered at $1 \mathrm{~h}$ before injection of Carrageenan. (A) Total Glutathione (GSH) contents. (B) CAT activity. (C) SOD activity. (D) MDA levels. (E) SOD/MDA ratio. Vinpo30; Vinpocetine at dose 30 $\mathrm{mg} / \mathrm{kg}$, and Vinpo100; Vinpocetine at dose 100 $\mathrm{mg} / \mathrm{kg}$. Data are expressed as the mean \pm S.D. of 6 mice for each group. $* * * \mathrm{p}<0.001$, compared with vehicle/or positive control. 
Effects of Vinpocetine on pro-inflammatory cytokines biomarkers in the paw

The most implicated inflammatory cytokines include TNF- $\alpha$, IL- 6 , and IL-1 $\beta$, were assessed in the hind paw tissue and presented in Fig. 5.

Sub-plantar injection of carrageenan meaningfully increased the tissue level of IL-1 $\beta$ (Fig. 5 A), IL-6 (Fig. 5B), and TNF$\alpha$ (Fig. 5C), with a values of $102 \pm 5.70$, $95.2 \pm 11.39 \mathrm{pg} / \mathrm{g}$, and $123 \pm 5.70 \mathrm{pg} / \mathrm{g}$, respectively, in comparison to control group $(29.4 \pm 3.56,20 \pm 3.54 \mathrm{pg} / \mathrm{g}$, and 41.9 $\pm 7.54 \mathrm{ng} / \mathrm{g}$ ). As anticipated, administration of Vinpo, $1 \mathrm{hr}$ before carrageenan injection, was mitigated the augmentation of IL- $1 \beta$, IL-6, and TNF- $\alpha$ in the hind paw tissue with a values of $25.46 \pm 2.03,23.46 \pm 2.98 \mathrm{pg} / \mathrm{g}$, and $49.52 \pm 7.56 \mathrm{ng} / \mathrm{g}$ respectively. The reduction in the above-mentioned parameters was pronounced in Vinpo 100treated group (43.26, 24.09, and 22.01\%), moderate in Vinpo 30- treated group (51.44, 40.18, and $27.68 \%$ ) and mild in Vinpotreated 3, 10 group $(132.16,95.12$, and $82.75 \%)$.

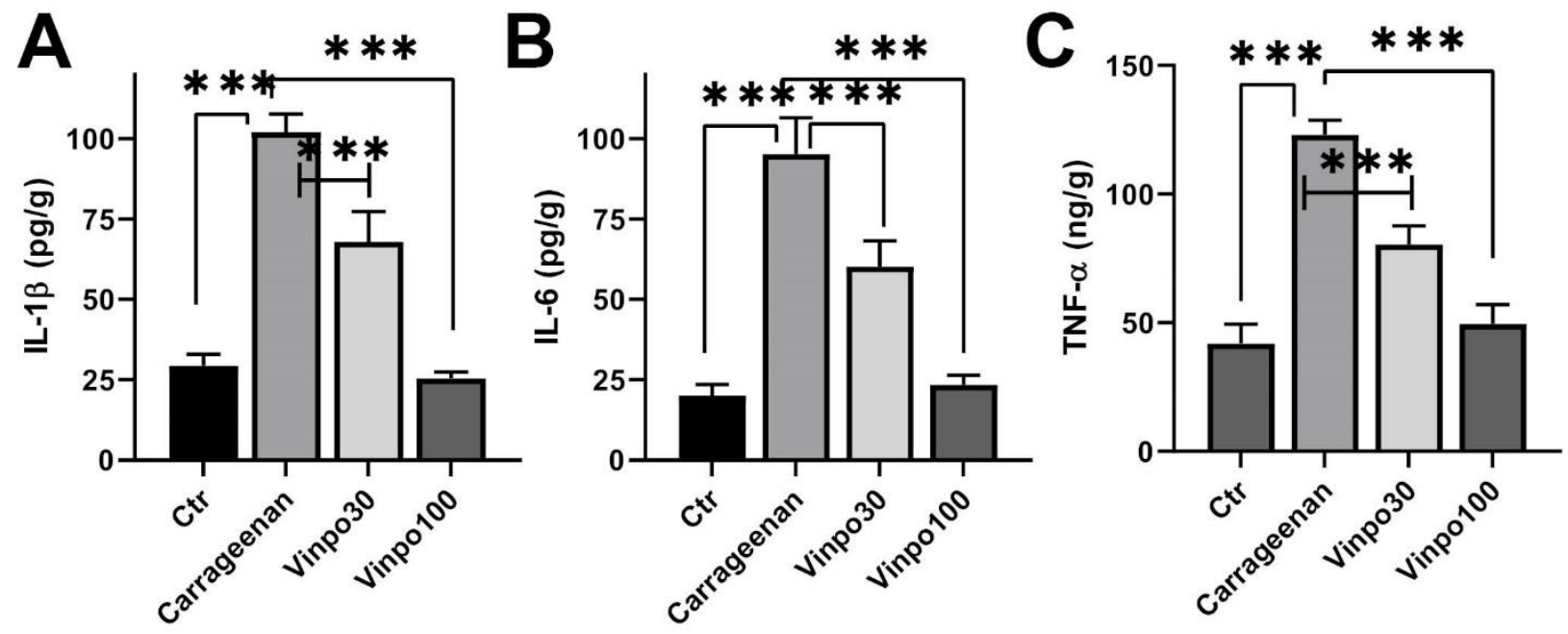

Fig. 5. Effects of Vinpocetine on pro-inflammatory cytokines (IL-1ß, IL-6, and TNF- $\alpha$ ), in CGN-induced paw edema

The mice were pretreated with Vinpocetine at doses of 30, and $100 \mathrm{mg} / \mathrm{kg}$, intraperitoneally $1 \mathrm{hr}$ before injection of Carrageenan. (A) IL-1 $\beta$ contents. (B) IL-6 contents. (C) TNF- $\alpha$ contents. Data are expressed as the mean \pm S.D. of 6 mice for each group. $* * * p<0.001$, compared with vehicle/or positive control.

\section{Effects of Vinpocetine on the protein expression of $C O X-2$ in the paw of $C G N$ - challenged mice}

To evaluate the potential role of COX2 expression in the anti-inflammatory protection of Vinpo, we examined the protein levels of COX-2 in the paw. The results revealed that Vinp significantly reduced the $\mathrm{CGN}$-induced increase $\mathrm{COX}-2$ expression (Fig. 6A-B). Western Blots analyses show that Vinpo inhibited the protein expression of COX-2 in the paw in a dose-dependent manner, with maximum effect can be achieved by using $100 \mathrm{mg} / \mathrm{kg}$ of Vinpo. By calculation of arbitrary unit, Fig. 6B shows that Vinpo at different 
concentrations $\quad(10, \quad 30, \quad 100 \quad \mathrm{mg} / \mathrm{kg})$ significantly $(\mathrm{p}<0.05$ and $\mathrm{p}<0.01)$ decreased CGN-induced overexpression of COX-2 protein $(0.68 \pm 0.12$, arbitrary unit $)$ in the paw, with arbitrary unit of $0.49 \pm$ $0.12, \quad 0.39 \pm 0.05$ and $0.18 \pm 0.04$, respectively, in comparison to control group $(0.15 \pm 0.04$ arbitrary unit).

To confirm the downregulation of COX-2 protein expression, we evaluated
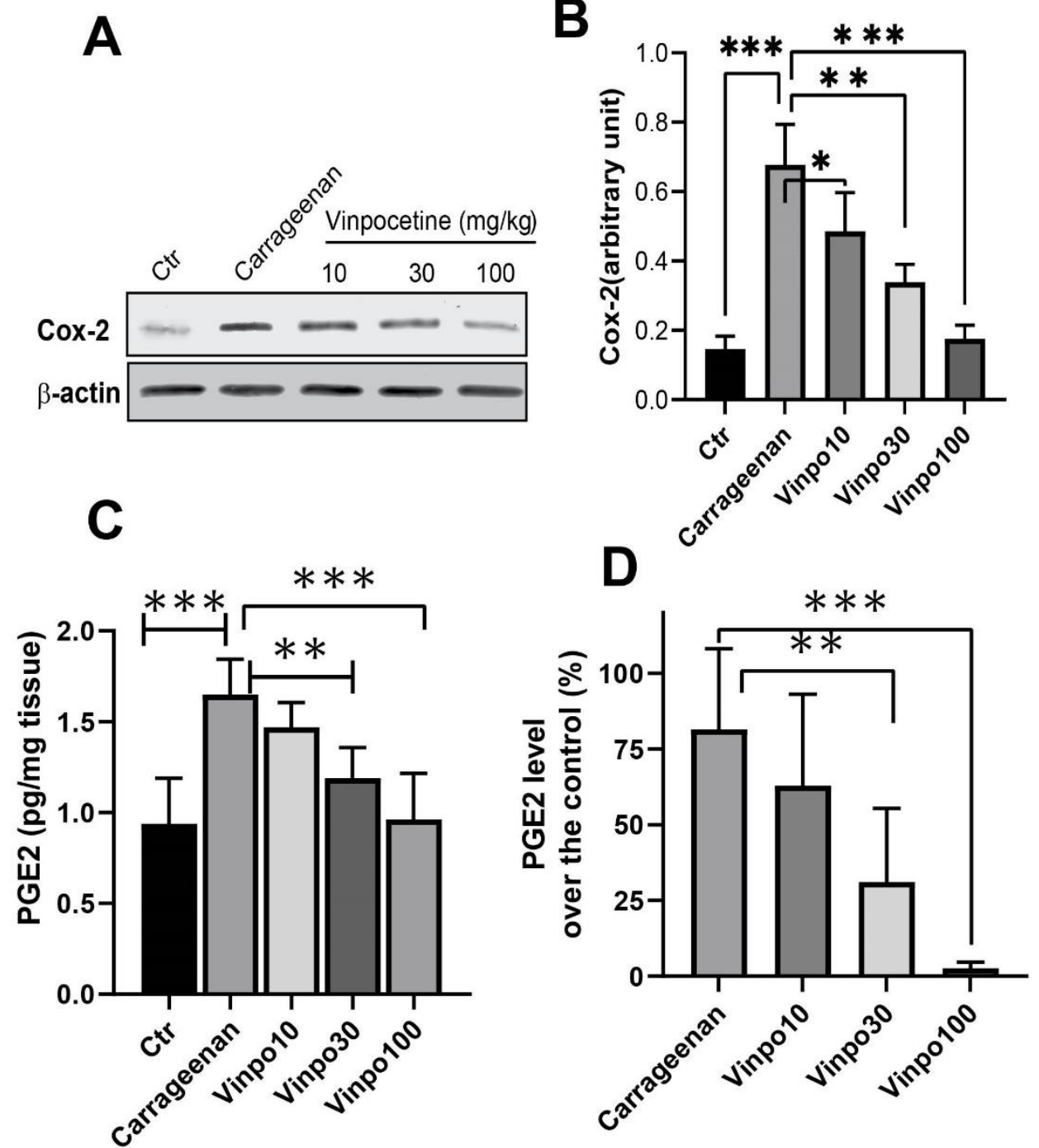

Fig. 6. Effects of Vinpocetine on COX-2 expression and PGE2 level in the paw of CGNtreated mice. (A) COX2 protein expression. (B) Calculated arbitrary unit. (C) PGE2 levels in the paw of Carr-treated mice. D) Percentage of EPGE2 levels in the paw of CGN -treated mice. The values are presented as the mean \pm SD. $* * p<0.01$, ***p $<0.01$ compared with the carrageenan group. Vinpo10; Vinpocetine at dose $10 \mathrm{mg} / \mathrm{kg}$, Vinpo30; Vinpocetine at dose 30 $\mathrm{mg} / \mathrm{kg}$, and Vinpo100; Vinpocetine at dose $100 \mathrm{mg} / \mathrm{kg}$. Data are expressed as the mean \pm S.D. of 6 mice for each group. ${ }^{*} \mathrm{p}<0.05,{ }^{*} \mathrm{p}<0.01$ and $* * * \mathrm{p}<0.001$ compared with vehicle/or positive control. 
To clarify the possible interaction between Vinpocetine and COX-2 protein, the Molecular Docking approach was employed. Vinpo and Diclofenac were docked against COX-2 (1PXX, Fig. 7A) and the results obtained as binding affinity and binding interactions (Fig. 7 and Table 1). It has been established that the lower binding energy value, the higher binding affinity. Vinpo showed relative closed binding energy value (- 6.5 $\mathrm{kcal} / \mathrm{mol}$ ), with $\mathrm{COX}-2$, in comparison to diclofenac $(-7.3 \mathrm{kcal} / \mathrm{mol})$, displaying a reasonably binding of Vinpo with COX-2 .

A
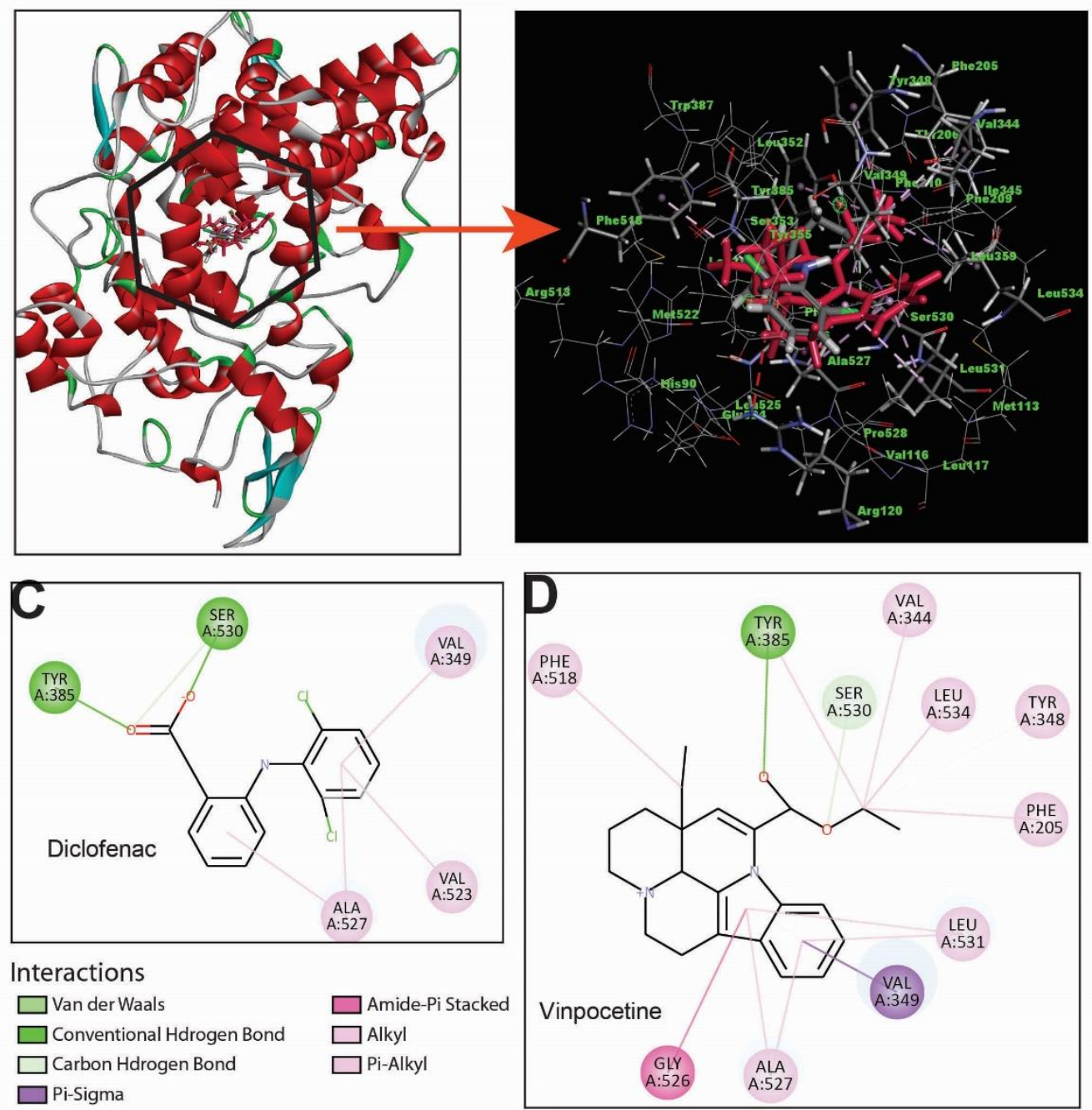

\section{Fig. 7. Molecular docking}

Molecular docking of Vinpocetine and diclofenac; (A) Vinpocetine and diclofenac within the active binding site of COX-2 enzyme (PDB ID: 1PXX). B) Vinpocetine and diclofenac were surrounded with pocket atoms (amino acids) of the binding site of 1PXX. C) Binding interactions of diclofenac with COX-2(1PXX), 2D presentation. D) Binding interactions of Vinpocetine with COX-2(1PXX), 2D presentation. 


\section{Table 1. Molecular docking analysis of Vinpocetine and Diclofenac with COX-2 interaction}

\begin{tabular}{|l|r|l|l|}
\hline \multicolumn{4}{|c|}{ Vinpocetine } \\
\hline Amino acid Residue & Distance & \multicolumn{1}{|c|}{ Category } & \multicolumn{1}{|c|}{ Type of interaction } \\
\hline SER530 & 1.68377 & Hydrogen Bond & Conventional Hydrogen Bond \\
\hline TYR355 & 2.11015 & Hydrogen Bond & Carbon Hydrogen Bond \\
\hline VAL349 & 2.32875 & Hydrophobic & Pi-Sigma \\
\hline ALA527 & 3.58484 & Hydrophobic & Pi-Alkyl \\
\hline LEU531 & 3.74914 & Hydrophobic & Pi-Alkyl \\
\hline LEU531 & 3.87934 & Hydrophobic & Pi-Alkyl \\
\hline VAL349 & 4.26216 & Hydrophobic & Pi-Alkyl \\
\hline LEU534 & 4.28034 & Hydrophobic & Alkyl \\
\hline VAL344 & 4.3012 & Hydrophobic & Alkyl \\
\hline VAL523 & 4.34788 & Hydrophobic & Alkyl \\
\hline LEU352 & 4.39384 & Hydrophobic & Alkyl \\
\hline PHE518 & 4.67865 & Hydrophobic & Pi-Alkyl \\
\hline PHE205 & 4.82993 & Hydrophobic & Pi-Alkyl \\
\hline TYR348 & 5.35403 & Hydrophobic & Pi-Alkyl \\
\hline ILE345 & 5.38392 & Hydrophobic & Pi-Alkyl \\
\hline & \multicolumn{3}{|c|}{ Diclofenac } \\
\hline Amino acid Residue & Distance & Category & Type of interaction \\
\hline SER530 & 1.70929 & Hydrogen Bond & Conventional Hydrogen Bond \\
\hline TYR385 & 2.19089 & Hydrogen Bond & Conventional Hydrogen Bond \\
\hline SER530 & 2.9693 & Hydrogen Bond & Carbon Hydrogen Bond \\
\hline ALA527 & 3.77433 & Hydrophobic & Pi-Alkyl \\
\hline VAL349 & 5.63307 & Hydrophobic & Pi-Alkyl \\
\hline ALA527 & 5.33218 & Hydrophobic & Pi-Alkyl \\
\hline VAL523 & \multicolumn{3}{|l}{} \\
\hline
\end{tabular}

\section{Discussion}

An inflammatory process is one of the most common processes involved in many diseases and medical disorders. Acute inflammatory response is one of the earliest reactions to cellular injury and is usually represented by an intensive migration of plasma and immune cells, from the blood circulation, into the injured tissues. Cardinal signs of inflammation include tenderness, swelling, heat, redness, and loss of function. In addition, the recruitment of leukocytes to the injured areas of the body is an important non-clinical indicator of inflammation. At the onset of inflammation, the resident-cells in the injured tissue release inflammatory cytokines that signal the threat to neighboring cells, triggering their defense responses. Upon the release of cytokines, cytokines stimulate the endothelial cells to express cell adhesion molecules (CAMs) and to chemoattract leukocytes to injured tissue. In acute inflammation, leukocytes are mainly neutrophils (Medzhitov, 2008, Nathan, 2002, 
Yoshikawa, 2006, Zhan et al., 2004). At the inflammatory site, neutrophils generate reactive oxygen species (ROS) such as superoxide anion $\left(\mathrm{O}_{2}{ }^{--}\right)$and nitric oxide (NO), which induce cellular and tissue damage by oxidative stress. Due to the detrimental effects of acute inflammation responses, anti-inflammatory agents serve as a useful clinical tool for treating inflammation and reducing tissue damage. Even though anti-inflammatory drugs control inflammation, they cause many side effects that lessen their clinical use (Bindu et al., 2020, Zingler et al., 2016, Koffeman et al., 2015, Sostres et al., 2010). Consequently, the need for new antiinflammatory drugs remains essential.

In order to assess the effects of vinpocetine on inflammation, two standard and classic models were selected; xyleneinduced ear edema and CGN-induced paw edema, both of which are authoritative models.

Xylene-induced ear edema has been extensively used to screen new antiinflammatory drugs in mice, where Xylene increases capillary permeability and leukocyte infiltration. Based on our study, Vinpocetine significantly reduced the edema of the ears in mice in a dose-dependent manner, suggesting that vinpocetine has a potential anti-inflammatory effect (Fig. 1AD).

It is known that the increase in vascular permeability caused by the acetic acid leads to early exudative inflammation and, conversely, its inhibition leads to the reduction of edema size and to reduced neutrophil migration. Therefore, Vinpocetine might have an antiinflammatory effect, in part, by reducing vascular permeability, which is documented by reducing dye leakage in the acetic acid model (Fig. 1E).

CGN-induced paw edema is timedependent experiment and has biphasic stages of inflammatory reaction, with numerous mediators contributing to its progression (Roach and Sufka, 2003). During the first hour of inflammation (first phase, 0-1 hour), inflammation is accompanied by significant edema formation, which is due to rapid release of inflammatory mediators, such as bradykinin, histamine, and 5-HT (serotonin) (Sadeghi et al., 2013, Di Rosa et al., 1971, Gilligan et al., 1994, Chang et al., 2012), while The second inflammatory stage (2-6 h) characterized by the release of arachidonate-metabolites such as prostaglandins and various cytokines; such as IL-1 $\beta$, IL-6, IL-10 and TNF- $\alpha$ and nitric oxide, induced by $\mathrm{COX}-2$ and nitric oxide synthase (iNOS) (Vircheva et al., 2012, Di Rosa et al., 1971, Gilligan et al., 1994, Chang et al., 2012). In the current work, Vinpocetine exerts prominent inhibitory effects on the CGN-induced paw edema in both inflammatory phases (Fig. 2B). Therefore, it is plausible that Vinpocetine diminished the release of proinflammatory mediators that may be involved in the two phases of the CGNinduced inflammation, in a dose-dependent manner, with prominent effect in second phase.

Pro-inflammatory Cytokines are key factors in the disease process, and their increased levels are implicated to a worse prognosis. Therefore, it is essential to suppress pro-inflammatory cytokines in order to regulate and manage both acute and chronic inflammatory responses. In the current investigation, pretreatment of CGNtreated mice with Vinpocetine showed potent anti-inflammatory activities (Fig. 3) associated with inhibition the overproduction of the pro-inflammatory cytokines (IL-1 $\beta$, IL-6, and TNF- $\alpha$ ) in the inflamed paw skin (Fig. 5).

Recent evidence shows that excessive release of ROS following carrageenan injection results in inflammation due to activation of immune cells and release of 
various pro-inflammatory cytokines, resulting in tissue injury. In the existing study, carrageenan injected mice showed an overproduction of pro-inflammatory cytokines (IL-1 $\beta$, IL-6, and TNF- $\alpha$ ) and a significant increase in the levels of MDA and MPO activity. Several antioxidant defense mechanisms have been developed in cells to limit ROS generation and to combat ROS formation; the system comprises multiple enzyme systems involved in converting ROS to less reactive molecules such as $\mathrm{O}_{2}$ and water (Valerio et al., 2007). The first line of defense is created by SOD, catalase, and glutathione. SOD, is known as the most powerful antioxidant enzyme in the cell, that enhance the conversion of superoxide radicals/ or singlet-oxygen into hydrogen peroxide $\left(\mathrm{H}_{2} \mathrm{O}_{2}\right)$ and molecular oxygen; CAT catalyzes the degradation/reduction of $\mathrm{H}_{2} \mathrm{O}_{2}$ to water and molecular oxygen, in order to complete the detoxification process started by SOD, and GSH is no-enzymatic antioxidant molecule and is the most abundant intracellular nonprotein thiol. GSH works to eliminate potentially harmful electrophiles and metals, protecting the cells from toxic free radicals/toxic oxygen products (Zhan et al., 2004, Nathan, 2002, Vircheva et al., 2012). Thus, it is essential to restore balance between the antioxidant defense and the oxidant process to prevent oxidative stress and consequently tissue damage. In our investigation, inflammatory responses to carrageenan have been linked with increased production of both MDA level and MPO activity and decreased activity of both enzymatic antioxidants (SOD and CAT) as well as non-enzymatic antioxidants (GSH), However, this increase/decrease was greatly countered by intraperitoneal injection of Vinpocetine, suggesting that Vinpocetine may exert anti-inflammatory activity in part owing to its ability to inhibit CGN-induced oxidative stress (Fig. 4).

Results were confirmed by histopathological examination (Fig. 3), which showed pronounced inflammation in the carrageenan group, with marked edema and cellular infiltration. Meanwhile, Vinpocetine administration has restored the damaged tissues to normal skin architecture in a dose-dependent manner.

To determine how Vinpocetine suppresses CGN-induced paw edema, the immunoblot assay was employed to test Vinpocetine's effect on inducible COX-2 expression. Western blot analysis revealed that Vinpocetine could downregulate COX2 (Fig. 6A-B), in a dose dependent manner. PGE2, downstream a metabolite of COX-2, is one of the strongest inflammatory mediators in the inflammatory process. As shown in Fig. 6D, Vinpocetine significantly decreased the levels of PGE2, suggesting that COX-2 might be main target enzyme that could contribute to anti-inflammatory activity of Vinpocetine. Therefore, we next evaluate the potential interactions between Vinpocetine and $\mathrm{COX}-2$ protein using Molecular Docking approach. As showed in Fig. 7, Vinpocetine bind to active site of COX-2 (diclofenac binding site) with binding energy value $(-6.5 \mathrm{kcal} / \mathrm{mol})$. It is also found that Vinpocetine established strong and stable Conventional Hydrogen Bond and Carbon Hydrogen Bond with COX-2.

In conclusion, the results show that Vinpocetine was significantly effective at reducing the severity of CGN-induced acute paw edema in mice. These antiinflammatory effects of vinpocetine may result from inhibition of leukocyte cellular infiltration, increased non-enzymatic antioxidant GSH levels and subsequent reduced oxidative stress. Moreover, Vinpocetine suppressed COX-2/PGE2 signal pathway. Consequently, our findings offer new therapeutic perspectives on the use of Vinpocetine to treat acute inflammatory diseases/ or disorders. 


\section{Conflict of interest}

The authors declare that they do not have any conflict of interest.

\section{Financial Disclosure}

The authors certify that none of the parties with a direct interest in the results of the research supporting this article has or will confer a benefit on the authors or on any organization with which the authors are affiliated

\section{References}

Abdelmageed N, Twafik, WAA, Seddek A and Morad SAF (2021). Vinpocetine-based therapy is an attractive strategy against oxidative stress-induced hepatotoxicity in vitro by targeting Nrf2/HO-1. Pathway, 20: $550-561$.

Adegbaju OD, Otunola GA and Afolayan A J (2020). Anti-inflammatory and cytotoxic evaluation of extracts from the flowering stage of Celosia argentea. BMC Complement Med Ther, 20(1): 152.

Andrianova NV, Zorov DB and Plotnikov E Y (2020). Targeting Inflammation and Oxidative Stress as a Therapy for Ischemic Kidney Injury. Biochemistry (Mosc), 85(12): 15911602.

Aratani Y, Miura N, Ohno N and Suzuki K (2012). [Role of neutrophil-derived reactive oxygen species in host defense and inflammation]. Medical Mycology Journal, 53(2): 123-128.

Baptista A, Goncalves RV, Bressan J and Peluzio M (2018). Antioxidant and Antimicrobial Activities of Crude Extracts and Fractions of Cashew (Anacardium occidentale L.), Cajui (Anacardium microcarpum), and Pequi (Caryocar brasiliense C.): A Systematic Review', Oxid Med Cell Longev, 3753562.
Bindu S, Mazumder S and Bandyopadhyay U (2020). Non-steroidal antiinflammatory drugs (NSAIDs) and organ damage: A current perspective. Biochemistry and Pharmacology, 180: 114147.

Bryan N, Ahswin H, Smart N, Bayon Y, Wohlert S and Hunt JA (2012). Reactive oxygen species (ROS)--a family of fate deciding molecules pivotal in constructive inflammation and wound healing', Eureopean Cell Material, 24: 249-265.

Chang CW, Chang WT, Liao JC, Chiu YJ, Hsieh MT, Peng WH and Lin YC (2012). Analgesic and AntiInflammatory Activities of Methanol Extract of Cissus repens in Mice. Evid Based Complement Alternat Med, 135379.

Charlton A, Garzarella J, Jandeleit-Dahm K AM and Jha JC (2020). Oxidative Stress and Inflammation in Renal and Cardiovascular Complications of Diabetes, Biology (Basel), 10(1).

Chen L, Deng H, Cui H, Fang J, Zuo Z, Deng J, Li Y, Wang X and Zhao L (2018). Inflammatory responses and inflammation-associated diseases in organs. Oncotarget, 9(6): 7204-7218.

Chen S, Chen H, Du Q and Shen J (2020). Targeting Myeloperoxidase (MPO) Mediated Oxidative Stress and Inflammation for Reducing Brain Ischemia Injury: Potential Application of Natural Compounds. Frontier in Physiology, 11: 433.

Di Rosa M, Giroud JP and Willoughby DA (1971). Studies on the mediators of the acute inflammatory response induced in rats in different sites by carrageenan and turpentine', Journal of Pathology, 104(1): 15-29.

Dludla PV, Nkambule BB, Mazibuko-Mbeje SE, Nyambuya TM, Marcheggiani F, Cirilli I, Ziqubu K, Shabalala SC, Johnson R, Louw J, Damiani E and Tiano L (2020). N-Acetyl Cysteine Targets Hepatic Lipid Accumulation 
to Curb Oxidative Stress and Inflammation in NAFLD: A Comprehensive Analysis of the Literature. Antioxidants (Basel). 9(12).

Gilligan JP, Lovato SJ, Erion MD and Jeng AY (1994). Modulation of carrageenan-induced hind paw edema by substance $\mathrm{P}^{\prime}$, Inflammation, 18(3): 285-292.

Helm JS and Rudel RA (2020). Adverse outcome pathways for ionizing radiation and breast cancer involve direct and indirect DNA damage, oxidative stress, inflammation, genomic instability, and interaction with hormonal regulation of the breast. Archive of Toxicology, 94(5): 1511-1549.

Koffeman AR, Van Buul AR, Valkhoff VE, Jong GW, Bindels PJ, Sturkenboom MC, Van der Lei J, Luijsterburg PA and Bierma-Zeinstra SM (2015). Adverse drug reactions in a primary care population prescribed nonsteroidal anti-inflammatory drugs. Scandvian Journal Prim Health Care, 33(3): 163-169.

Lauridsen C (2019). From oxidative stress to inflammation: redox balance and immune system. Poultry Science, 98(10): 4240-4246.

Mazzaferro S, Bagordo D, De Martini N, Pasquali M, Rotondi S, Tartaglione L, Stenvinkel P (2021). Inflammation, Oxidative Stress, and Bone in Chronic Kidney Disease in the Osteoimmunology Era', Calcif Tissue Int.

Medzhitov R (2008). Origin and physiological roles of inflammation. Nature, 454(7203): 428-435.

Mittal M, Siddiqui MR, Tran K, Reddy SP and Malik AB (2014). Reactive oxygen species in inflammation and tissue injury. Antioxid Redox Signal, 20(7): 1126-1167.

Morad SA, Messner MC, Levin JC, Abdelmageed N, Park H, Merrill A
H, Jr. and Cabot MC (2013a) Potential role of acid ceramidase in conversion of cytostatic to cytotoxic end-point in pancreatic cancer cells', Cancer Chemotherapy Pharmacology, 71(3): 635-645.

Morad SA, Schmid M, Buchele B, Siehl H U, El Gafaary M, Lunov O, Syrovets $\mathrm{T}$ and Simmet $\mathrm{T}$ (2013b). A novel semisynthetic inhibitor of the FRB domain of mammalian target of rapamycin blocks proliferation and triggers apoptosis in chemoresistant prostate cancer cells. Molecular Pharmacology, 83(2): 531-541.

Nathan C (2002). Points of control in inflammation. Nature, 420(6917): 846-852.

Nidavani RB, Mahalakshmi A and Shalawadi M (2014). Vascular permeability and Evans blue dye: a physiological and pharmacological approach. Journal of Applied Pharmaceutical Science, 4(11): 106113.

Roach JT and Sufka KJ (2003). Characterization of the chick carrageenan response. Brain Research, 994(2): 216-225.

Sadeghi H, Hajhashemi V, Minaiyan M, Movahedian A and Talebi A (2013). Further studies on anti-inflammatory activity of maprotiline in carrageenan-induced paw edema in rat. International Immunopharmacol, 15(3): 505-510.

Sostres C, Gargallo CJ, Arroyo MT and Lanas A (2010). Adverse effects of non-steroidal anti-inflammatory drugs (NSAIDs, aspirin and coxibs) on upper gastrointestinal tract. Best Practical Research in Clinical Gastroenterology, 24(2): 121-132.

Valerio DA, Cunha TM, Arakawa NS, Lemos HP, Da Costa FB, Parada C A, Ferreira SH, Cunha FQ and Verri WA Jr. (2007). Anti-inflammatory and analgesic effects of the sesquiterpene lactone budlein $\mathrm{A}$ in 
mice: inhibition of cytokine production-dependent mechanism', European Journal of Pharmacology, 562(1-2): 155-163.

Vircheva S, Nenkova G, Georgieva A, Alexandrova A, Tzvetanova E, Mateeva P, Zamfirova $\mathrm{R}$ and Kirkova M (2012). Effects of desipramine on the antioxidant status in rat tissues at carrageenan-induced paw inflammation. Cell Biochemical Functions, 30(1): 18-23.

Yoshikawa $T$ (2006). Inflammation and oxidative stress. Nihon Naika Gakkai Zasshi, 95(9): 1870-1875.

Zhan CD, Sindhu RK, Pang J, Ehdaie A and Vaziri ND (2004). Superoxide dismutase, catalase and glutathione peroxidase in the spontaneously hypertensive rat kidney: effect of antioxidant-rich diet. Journal of Hypertension, 22(10): 2025-2033.

Zhang F, Yan C, Wei C, Yao Y, Ma X, Gong Z, Liu S, Zang D, Chen J, Shi FD and Hao J (2018). Vinpocetine Inhibits NF-kappaB-Dependent

Inflammation in Acute Ischemic Stroke Patients. Transl Stroke Research, 9(2): 174-184.

Zingler G, Hermann B, Fischer $\mathrm{T}$ and Herdegen T (2016). Cardiovascular adverse events by non-steroidal antiinflammatory drugs: when the benefits outweigh the risks. Expert Review Clinical Pharmacology, 9(11): 1479-1492. 